IOS Press

\title{
Hypothesis
}

\section{Brain Stress Mapping in COVID-19 Survivors Using MR Spectroscopy: New Avenue of Mental Health Status Monitoring $\$$}

\author{
Avantika Samkaria ${ }^{a}$, Khushboo Punjabi ${ }^{a}$, Shallu Sharma ${ }^{a}$, Shallu Joon ${ }^{a}$, Kanika Sandal ${ }^{a}$, \\ Tirthankar Dasgupta ${ }^{\mathrm{b}}$, Pooja Sharma ${ }^{\mathrm{c}}$ and Pravat K. Mandal ${ }^{\mathrm{a}, \mathrm{d}, *}$ \\ ${ }^{a}$ Neuroimaging and Neurospectroscopy (NINS) Laboratory, National Brain Research Centre, Gurgaon, India \\ ${ }^{\mathrm{b}}$ Moner Alo, Psychiatric Clinic, Kolkata, West Bengal, India \\ ${ }^{\mathrm{c}}$ Medanta Institute of Education and Research, Medicity, Gurgaon, India \\ ${ }^{\mathrm{d}}$ Florey Institute of Neuroscience and Mental Health, Melbourne School of Medicine Campus, \\ Melbourne, Australia
}

Accepted 29 June 2021

Pre-press 9 July 2021

\begin{abstract}
Coronavirus (COVID-19) has emerged as a human catastrophe worldwide, and it has impacted human life more detrimentally than the combined effect of World Wars I and II. Various research studies reported that the disease is not confined to the respiratory system but also leads to neurological and neuropsychiatric disorders suggesting that the virus is potent to affect the central nervous system (CNS). Moreover, the damage to CNS may continue to rise even after the COVID-19 infection subsides which may further induce a long-term impact on the brain, resulting in cognitive impairment. Neuroimaging techniques is the ideal platform to detect and quantify pathological manifestations in the brain of COVID-19 survivors. In this context, a scheme based on structural, spectroscopic, and behavioral studies could be executed to monitor the gradual changes in the brain non-invasively due to COVID-19 which may further help in quantifying the impact of COVID19 on the mental health of the survivors. Extensive research is required in this direction for identifying the mechanism and implications of COVID-19 in the brain. Cohort studies are urgently required for monitoring the effects of this pandemic on individuals of various subtypes longitudinally.
\end{abstract}

Keywords: Brain, cognition, COVID-19, gamma-aminobutyric acid, glutathione, magnetic resonance spectroscopy, mental health, psychiatry

\footnotetext{
\$Prof. Pravat Mandal dedicates this article to the fond memory of Prof. Partha Raghunathan, a brilliant mind, who left us due to COVID-19.

*Correspondence to: Pravat Kumar Mandal, Professor and Scientist VII, Neuroimaging and Neurospectroscopy Laboratory, National Brain Research Centre, India. E-mails: pravat.mandal@ gmail.com, pravat@nbrc.ac.in; Honorary Professor, Florey Institute of Neuroscience and Mental Health, Melbourne School of Medicine Campus, Melbourne, Australia. E-mail: pravat.mandal @ florey.edu.au.
}

\section{INTRODUCTION}

Coronavirus (COVID-19) is an infectious disease caused by severe acute respiratory syndrome corona virus-2 (SARS-CoV-2). COVID-19 came into existence from Wuhan City, China in December 2019 [1]. The World Health Organization (WHO) declared COVID-19 a pandemic on 11 March 2020 due to the continual dissemination of this disease throughout the world [2]. According to 
the WHO, as of 29 June 2021, a total of $181,176,715$ cases including 3,930,496 deaths have been confirmed globally due to COVID-19, where $30,316,897$ cases with 397,637 fatalities are reported solely from India [3]. A variety of precautionary measures have been outlined by the WHO to protect humans from this infectious disease such as social distancing, wearing a mask, avoiding crowds, and regular cleaning of hands, etc. [4]. Despite considering these protective measures, the virus is still continuously spreading worldwide and the number of individuals affecting by COVID-19 is increasing day by day. The mortality rate is too high in elderly patients with low immunity due to nutritional deficiencies [5]. In view of this, the identification of effective drugs is vital for eradicating viral load from the body of the individuals affected with COVID19 [6]. According to the WHO, a total of fifteen vaccines have been developed up to now and some of them are approved to use on an emergency basis from the United States of America, Germany, United Kingdom, Russia, China and India.

The main characteristic of this disease is pneumonia [7]; however, cough, fever, dyspnea, anosmia, myalgia, sore throat, gastrointestinal penetrations, and rhinorrhea are the clinical manifestations that are possessed by an individual infected by COVID19 [2, 8-10]. The infection is not limited to the respiratory system but also adversely affects other vital organs such as the heart, liver, and kidney as well as brain [10-12]. Increased loneliness, isolation, distress, anxiety, and depression can trigger the onset of psychological illness in people [9, 13]. As a matter of this fact, post-traumatic stress disorder, depression, obsessive-compulsive disorder, and anxiety have been found as the most prevalent disorders in the patients recovered from COVID-19 [14-16].

Human ability to perceive, manage, update, and act on information in accordance with past experiences contribute to cognitive function which largely depends on the structural and functional integrity of the prefrontal cortex [17]. Exposure to stress can disrupt prefrontal cortex (PFC) function, causing cognitive impairments [18, 19]. Numerous mental illnesses_-including obsessive-compulsive disorder, depression, and anxiety disorders, etc., are characterized by PFC dysfunction [20]. Two recent studies, one from the ward of a general hospital and the other from a temporary quarantine facility, have shown that as high as $9.4 \%, 15.1 \%, 24.5 \%$, and $96.2 \%$ of the COVID-19 patients had severe depressive, anxiety, and post-traumatic stress disorder symptoms.
COVID-19 itself can put a lot of stress on the brain due to lockdown and complete isolation [21-23]. Many researchers and scientists have determined the presence of the SARS-CoV-2 virus in a variety of brain tissues such as cerebrospinal fluid (CSF), glial, and neuronal cells via genomic sequencing which is indicative of serious damage to the CNS [24]. The presence of SARS-CoV-2 RNA in CSF suggests a possible association of SARS-CoV-2 infection with neurological symptoms in COVID-19 patients [10, 25-27].

The FLAIR and diffusion weighted images have also reported non confluent multifocal white matter hyper-intensities in the affected individuals along with other imaging alterations [8, 28-30]. Moreover, the damage to CNS may continue to rise even after the pulmonary infection subsides. COVID-19 infection in the brain can be associated with extreme physical and psychological stress which stimulates the hypothalamic-pituitary-adrenal axis and aggravates neuroinflammation [31]. It is important to note from a previous study that cognitive disorders and neuroinflammation are correlated with each other [9, 32]. A significant decline in cognitive functioning has also been identified through low scores of neuropsychological tests (continuous performance test), greater reaction time, a deficit in attention and executive functioning of COVID19 recovered patients [21, 22, 33-36]. Structural changes have also been determined in the brain of COVID-19 patients as compared to the non-infected ones from a variety of studies where the researchers claimed enlarged volumes of several brain regions like the hippocampus, Heschl's gyrus, olfactory cortices, cingulate gyrus, and Rolandic operculum [23, 37]. Anatomically distinct regions of the nasopharynx and brain show the presence of SARS-CoV-2 RNA and protein. This has been confirmed by the autopsy studies of the patients [37]. Furthermore, a description of morphological changes related to the infection such as thromboembolic ischemic infarction of the CNS has been given. This suggests the evidence of SARS-CoV-2 neurotropism. A metaanalysis study indicates that no virus is present in the CSF of patients and there is no direct neuroinvasion [38]. However, other groups of researchers have suggested that SARS-CoV-2 seems to follow neuroanatomical structures which further penetrates into defined neuroanatomical areas such as the primary respiratory and cardiovascular control center in the medulla oblongata [37, 39]. Therefore, it is important to implement long-term studies for determining 
the correlations among the clinical profile, laboratory investigations, and radiological observations besides neuropathological studies for an in-depth understanding of the neurological manifestations in the patients recovered from COVID-19. In this context, a scheme for examining the glutathione (GSH), glutamatergic, and GABAergic systems in hippocampal and dorsolateral prefrontal cortex (DLPFC) area of the brain has been proposed. Additionally, the implications of neuropsychological evaluation in diagnosing early mental health problems in COVID-19 survivors has also been outlined. The major rationale behind the proposed scheme is the increased level of oxidative stress in COVID-19 survivors which further contributes to the pathogenesis of several neurological diseases due to depletion of antioxidants.

\section{COVID-19 INFECTION IN BRAIN: A POSSIBLE MECHANISM}

Recent research findings suggest that coronavirus may enter the CNS via two pathways: direct [40] and indirect [41]. In the direct pathway, the virus may enter via the blood-brain barrier, blood-CSF barrier, and retrograde axonal transport to reach the neuronal cell bodies in the CNS (see Fig. 1). The olfactory, respiratory, and enteric nervous system networks are the three possible pathways through which retrograde axonal transport can occur [12-15]. Ongoing research suggests that SARS-CoV-2 is likely to enter the nervous system by crossing the neural-mucosal interface in olfactory mucosa, which subsequently deteriorates the close domain of olfactory endothelial, mucosal, and nervous tissue, involving the delicate sensory and olfactory nerve endings [37]. Other researchers have also reported that from the olfactory bulb, the virus may tend to target deeper parts of the brain such as the brainstem and thalamus by transsynaptic transfer which has also been described for several distinct viral diseases. They suggest that the infection of the respiratory center of the brain might take place which explains the respiratory breakdown in patients [42].

In respect to the indirect mechanisms, researchers proposed that respiratory failure-induced hypoxia and immune system malfunction may lead to neuronal damage $[4,43]$. The pro-inflammatory cytokines (IL- 6 and TNF- $\alpha$ ) are released in abundance in response to a viral infection which causes excessive

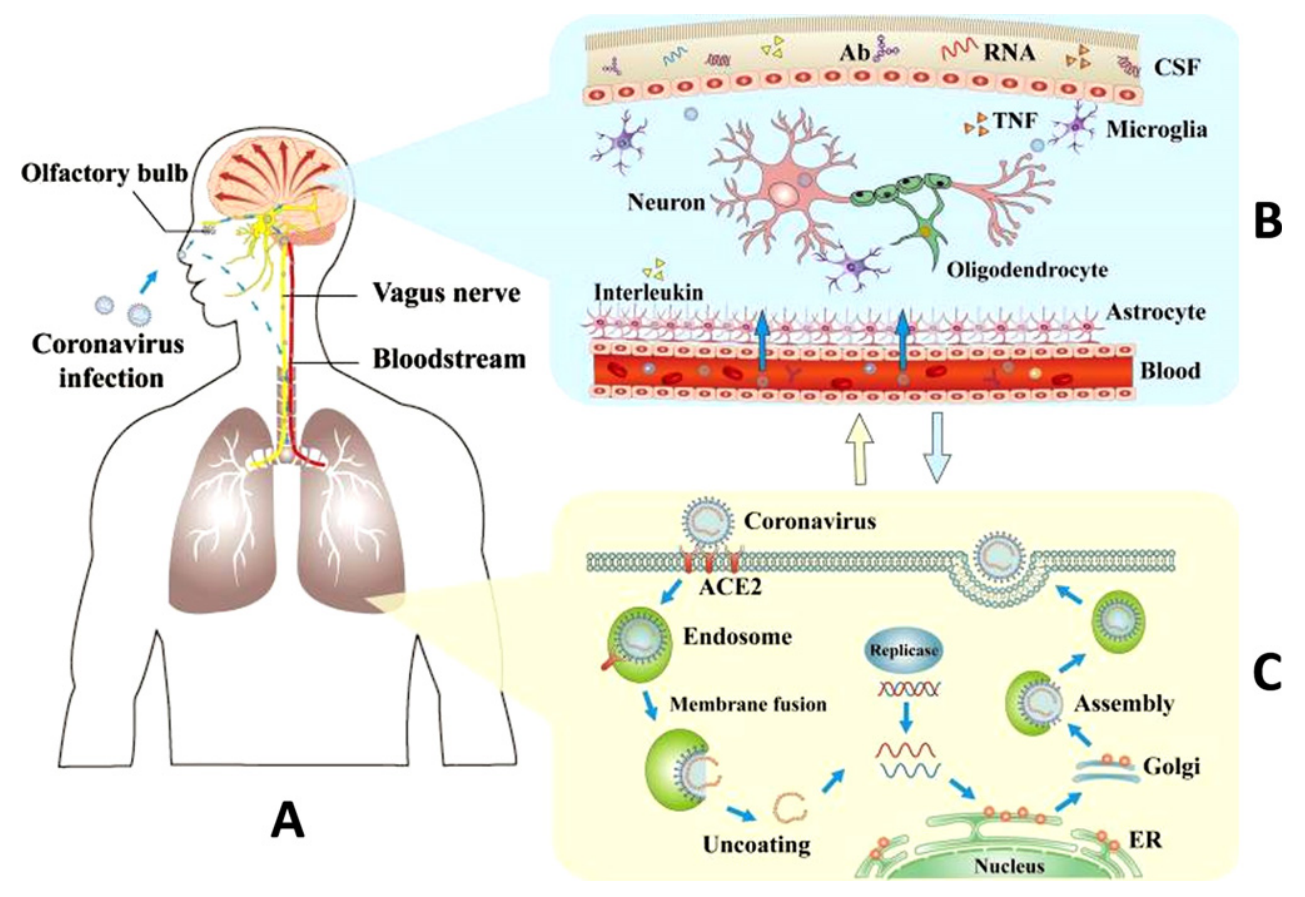

Fig. 1. A schematic representation of COVID-19 virus routes to the respiratory system and the brain. A) COVID-19 infection routes for brain and lung damage, B) invasion of the SARS-CoV-2 into the nervous system through the blood-brain barrier, and C) intrusion of SARS-CoV-2 into lungs by fusing with an angiotensin-converting enzyme (ACE2). Reproduced with permission from the publisher [40]. Ab, antibody; ACE2, angiotensin-converting enzyme 2; CSF, cerebrospinal fluid; ER, endoplasmic reticulum; TNF, tumor necrosis factor. 
inflammation of the blood-brain barrier [10, 41]. Consequently, the permeability of the blood-brain barrier is increased which further provides a pathway for the virus to enter the brain indirectly. Infection of the peripheral myeloid cells is another possibility through which the virus may give rise to the psychiatric symptoms indirectly by causing neuroinflammation and virus-induced neuropathology [44].

\section{OXIDATIVE STRESS, ANTIOXIDANTS AND NEUROTRANSMITTERS}

Oxidative stress can be described as the increased production of reactive oxygen species and depletion of antioxidants which further contributes to the pathogenesis of several neurological diseases [5]. In patients infected with COVID-19, a high neutrophil to lymphocyte ratio has been observed which is strongly associated with an excessive level of reactive oxygen species. Consequently, the increasing load of viral infection causes a decrease in antioxidant defense. GSH deficiency appears to be a primary factor in enhancing SARS-CoV-2-induced oxidative damage which further gives rise to many clinical expressions such as multiorgan failure, acute respiratory distress syndrome, and even death in patients with COVID-19 infection [40]. GSH is the most important antioxidant in the human brain which plays a vital role in antioxidant defense. A variety of studies related to postmortem and neurological disorders have observed a significant depletion in GSH through magnetic resonance spectroscopy (MRS) [45]. Detection of extended and closed conformers of GSH has also been performed using the MEGA-PRESS sequence [46]. Alterations of GSH conformers is also detected [47]. Thus, measuring GSH for comparison between patient and control groups can be performed. Recently, it has also been found that GSH and its precursor's supplements aid in recovery from respiratory distress in patients infected with COVID-19 [48, 49]. GSH has been identified as a source that can inhibit the main protease (Mpro) of COVID-19 [50]. In this context, the use of GSH as a supportive strategy for the treatment of COVID-19 infection can be recommended after a successful trial.

Primary excitatory and inhibitory neurotransmitters, i.e., GABA and glutamate also play a key role in modulating activity in the brain circuitry $[51,52]$. Prolonged stress can cause loss of prefrontal glutamate transmission that may alter the hippocampal memory formation leading to dysfunction in cognitive function [53]. Dysfunction of the glutamatergic system can give rise to defects in neurotransmission, and cell viability which is further implicated in various psychiatric disorders [54]. Stress-induced alterations in the functionality of GABAergic inhibitory neurotransmission and synap-

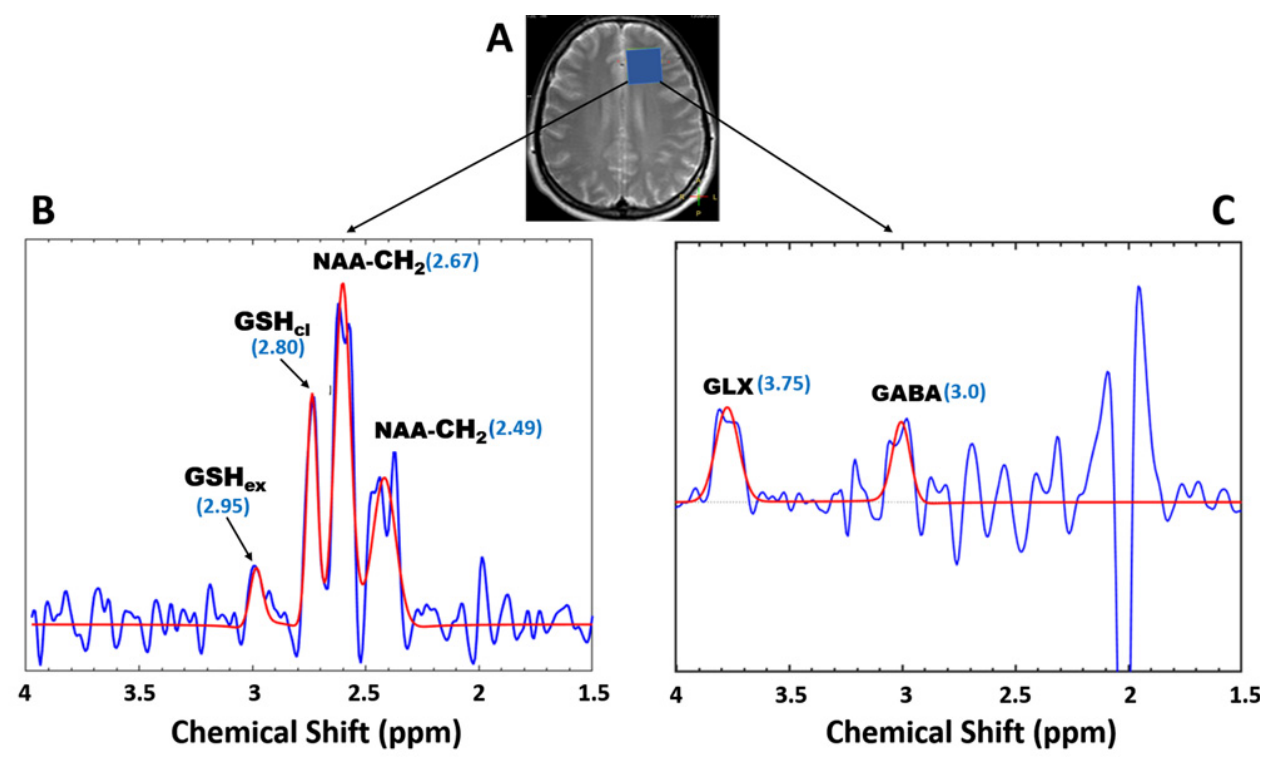

Fig. 2. Detection of GSH, GABA+, and Glx metabolite from the DLPFC of a healthy young volunteer using 3T (Philips, Innova) scanner at NBRC. A) T2w image with a voxel placed in DLPFC region in the brain for acquiring GSH and GABA. B) Closed and extended GSH conformers at 2.95 and $2.80 \mathrm{ppm}$ [46] with aspartate moiety signals from N-Acetyl-Aspartate at $2.67 \mathrm{ppm}$ (NAA). C) MRS signal representing the peaks of GABA and glutamine/glutamate (Glx) where the baseline spectra and fitted spectra are shown in blue and red, respectively. 
tic integrity in the PFC may lead to dysfunction of PFC microcircuitry. This may further trigger cognitive impairments due to disruption in the execution of behavioral responses [55]. Therefore, the level of glutamate and GABA can serve as a promising parameter to monitor mental health and psychiatric disease-associated conditions. SARS-CoV-2 has neurotrophic properties which cause various CNS manifestations including psychiatric diseases [56]. There has been growing evidence of patients suffering from psychiatric diseases possibly due to COVID-19 [57]. In view of this, the involvement of GABAgeric neuronal dysfunction in psychiatric disorders and associated mechanism has become an active area of research. Many studies have shown heterogeneous results while measuring the GABA level in patients with psychiatric disorders [58]. The level of GABA for some patients has increased while the GABA level remained unaltered for other patients. Hence, a longitudinal follow-up study can also be performed to correlate the GABA level with psychiatric problems.

All the above-discussed antioxidants and neurotransmitters have potential implications for psychiatric disorders in COVID-19 affected patients. Implementation and validation of imaging and spectroscopy technologies (MRI and MRS) can help in finding out structural as well as metabolic changes in the brain [59]. Literature describing the neurologic symptoms of COVID-19 infection is increasing rapidly. Despite this, there are only a few published sources that demonstrate the findings based on neuroimaging techniques to monitor neurological infection in COVID-19 patients [29]. Researchers are analyzing the hyperintensities from FLAIR images and metabolites information from single-voxel MRS which indicates the changes in structure and the level of metabolites in the brain, respectively [60, 61]. Based on the prior knowledge, we are proposing a scheme for examining the GSH, glutamatergic systems in the hippocampal and dorsolateral prefrontal cortex area of the brain. Additionally, a neuropsychological evaluation is also likely to help in diagnosing the mental health problems in COVID-19 survivors [62].

\section{CONCLUSION}

In this COVID-19 pandemic situation, worldwide intense efforts have helped to detect the pathology of the SARS-CoV-2 virus in humans and determined the post-recovery effects of the virus on their men- tal health. A variety of case studies and reports have suggested a probable relationship between the viral infection due to SARS-CoV-2, oxidative stress, and neurological symptoms. The possibility of gradual damage to the brain and indistinct neurologic clinical manifestation requires further investigation to determine its long-term neurologic consequences. The non-invasive imagining-based strategy supported by psychiatric and neuropsychological evaluation could be a combined initiative in the direction of finding a correlation between the alteration in antioxidant's and neurotransmitters' concentration besides the structural changes in the brain to quantify the neurological impact caused by the virus on the mental health of COVID-19 survivors. This manuscript is a sincere attempt to highlight the impact of the SARS-CoV-2 for neurological and neuropsychiatric manifestation to make a top research priority. We have initiated cohort study specifically focused on mental health monitoring using brain structural and neurochemical data by MRI/MRS and behavioral data analysis longitudinally.

\section{ACKNOWLEDGMENTS}

Dr. Pravat Mandal (Principal Investigator) thanks for partial financial support from various agencies (Tata Innovation grant, and Indo Australian strategic funding to PKM). Thanks to the computing support of NBRC for basic infrastructure support.

Authors' disclosures available online (https:// www.j-alz.com/manuscript-disclosures/21-0287r1).

\section{REFERENCES}

[1] Harapan H, Itoh N, Yufika A, Winardi W, Keam S, Te H, Megawati D, Hayati Z, Wagner AL, Mudatsir M (2020) Coronavirus disease 2019 (COVID-19): A literature review. J Infect Public Health 13, 667-673.

[2] Ortiz-Prado E, Simbaña-Rivera K, Gómez-Barreno L, Rubio-Neira M, Guaman LP, Kyriakidis NC, Muslin C, Jaramillo AMG, Barba-Ostria C, Cevallos-Robalino D (2020) Clinical, molecular and epidemiological characterization of the SARS-CoV2 virus and the Coronavirus disease 2019 (COVID-19), a comprehensive literature review. Diagn Microbiol Infect Dis 98, 115094.

[3] Guedj E, Million M, Dudouet P, Tissot-Dupont H, Bregeon F, Cammilleri S, Raoult D (2021) (18)F-FDG brain PET hypometabolism in post-SARS-CoV-2 infection: Substrate for persistent/delayed disorders? Eur J Nucl Med Mol Imaging 48, 592-595.

[4] Bougakov D, Podell K, Goldberg E (2021) Multiple neuroinvasive pathways in COVID-19. Mol Neurobiol 58, 564-575. 
[5] Polonikov A (2020) Endogenous deficiency of glutathione as the most likely cause of serious manifestations and death in COVID-19 patients. ACS Infect Dis 6, 15581562.

[6] Flanagan KL, Best E, Crawford NW, Giles M, Koirala A, Macartney K, Russell F, Teh BW, Wen SC (2020) Progress and pitfalls in the quest for effective SARS-CoV-2 (COVID19) vaccines. Front Immunol 11, 579250.

[7] Norooznezhad AH, Najafi F, Riahi P, Moradinazar M, Shakiba E, Mostafaei S (2020) Primary symptoms, comorbidities, and outcomes of 431 hospitalized patients with confirmative RT-PCR results for COVID-19. Am J Trop Med Hyg 103, 834-837.

[8] Chen B, Chen C, Zheng J, Li R, Xu J (2020) Insights into neuroimaging findings of patients with Coronavirus disease 2019 presenting with neurological manifestations. Front Neurol 11, 593520.

[9] Zhang H, Du F, Cao XJ, Feng XL, Zhang HP, Wu ZX, Wang BF, Zhang HJ, Liu R, Yang JJ, Ning B, Chen K, Huang ZP (2021) Clinical characteristics of coronavirus disease 2019 (COVID-19) in patients out of Wuhan from China: A case control study. BMC Infect Dis 21, 207.

[10] Moriguchi T, Harii N, Goto J, Harada D, Sugawara H, Takamino J, Ueno M, Sakata H, Kondo K, Myose N, Nakao A, Takeda M, Haro H, Inoue O, Suzuki-Inoue K, Kubokawa K, Ogihara S, Sasaki T, Kinouchi H, Kojin H, Ito M, Onishi H, Shimizu T, Sasaki Y, Enomoto N, Ishihara H, Furuya S, Yamamoto T, Shimada S (2020) A first case of meningitis/encephalitis associated with SARS-Coronavirus-2. Int $J$ Infect Dis 94, 55-58.

[11] Behzad S, Aghaghazvini L, Radmard AR, Gholamrezanezhad A (2020) Extrapulmonary manifestations of COVID-19: Radiologic and clinical overview. Clin Imaging 66, 35-41.

[12] Katal S, Balakrishnan S, Gholamrezanezhad A (2020) Neuroimaging and neurologic findings in COVID-19 and other coronavirus infections: A systematic review in 116 patients. J Neuroradiol 48, 43-50.

[13] Steardo L Jr, Steardo L, Verkhratsky A (2020) Psychiatric face of COVID-19. Transl Psychiatry 10, 261.

[14] Mazza MG, De Lorenzo R, Conte C, Poletti S, Vai B, Bollettini I, Melloni EMT, Furlan R, Ciceri F, Rovere-Querini P; COVID-19 BioB Outpatient Clinic Study group, Benedetti F (2020) Anxiety and depression in COVID-19 survivors: Role of inflammatory and clinical predictors. Brain Behav Immun 89, 594-600.

[15] Zandifar A, Badrfam R, Yazdani S, Arzaghi SM, Rahimi F, Ghasemi S, Khamisabadi S, Mohammadian Khonsari N, Qorbani M (2020) Prevalence and severity of depression, anxiety, stress and perceived stress in hospitalized patients with COVID-19. J Diabetes Metab Disord 19, 1-8.

[16] Parra A, Juanes A, Losada C, Álvarez-Sesmero S, Santana VD, Martí I, Urricelqui J, Rentero D (2020) Psychotic symptoms in COVID-19 patients. A retrospective descriptive study. Psychiatry Res 291, 113254.

[17] Goldman-Rakic PS (1996) The prefrontal landscape: Implications of functional architecture for understanding human mentation and the central executive. Philos Trans $R$ Soc Lond B Biol Sci 351, 1445-1453.

[18] Arnsten AF (2009) Stress signalling pathways that impair prefrontal cortex structure and function. Nat Rev Neurosci 10, $410-422$

[19] Arnsten AF, Wang MJ, Paspalas CD (2012) Neuromodulation of thought: Flexibilities and vulnerabilities in prefrontal cortical network synapses. Neuron 76, 223-239.
[20] Gao W-J, Wang H-X, Snyder MA, Li Y-C (2012) The unique properties of the prefrontal cortex and mental illness. In When Things Go Wrong - Diseases and Disorders of the Human Brain, Mantamadiotis T, ed. IntechOpen, doi: $10.5772 / 35868$

[21] Fernandez-Aranda F, Casas M, Claes L, Bryan DC, Favaro A, Granero R, Gudiol C, Jimenez-Murcia S, Karwautz A, Le Grange D, Menchon JM, Tchanturia K, Treasure J (2020) COVID-19 and implications for eating disorders. Eur Eat Disord Rev 28, 239-245.

[22] Bo HX, Li W, Yang Y, Wang Y, Zhang Q, Cheung T, Wu X, Xiang YT (2020) Posttraumatic stress symptoms and attitude toward crisis mental health services among clinically stable patients with COVID-19 in China. Psychol Med 51, 1052-1053.

[23] Qian Z, Caihong H, Renjie F, Yuan YJ (2020) Investigation of the mental health of patients with novel coronavirus pneumonia. Chinese J Neurol 12, E003.

[24] Baig AM, Khaleeq A, Ali U, Syeda H (2020) Evidence of the COVID-19 virus targeting the CNS: Tissue distribution, host-virus interaction, and proposed neurotropic mechanisms. ACS Chem Neurosci 11, 995-998.

[25] Fadakar N, Ghaemmaghami S, Masoompour SM, Shirazi Yeganeh B, Akbari A, Hooshmandi S, Ostovan VR (2020) A first case of acute cerebellitis associated with Coronavirus disease (COVID-19): A case report and literature review. Cerebellum 19, 911-914.

[26] Domingues RB, Mendes-Correa MC, de Moura Leite FBV, Sabino EC, Salarini DZ, Claro I, Santos DW, de Jesus JG, Ferreira NE, Romano CM, Soares CAS (2020) First case of SARS-COV-2 sequencing in cerebrospinal fluid of a patient with suspected demyelinating disease. J Neurol 267, 3154-3156.

[27] Virhammar J, Kumlien E, Fallmar D, Frithiof R, Jackmann S, Skold MK, Kadir M, Frick J, Lindeberg J, OliveroReinius H, Ryttlefors M, Cunningham JL, Wikstrom J, Grabowska A, Bondeson K, Bergquist J, Zetterberg H, Rostami E (2020) Acute necrotizing encephalopathy with SARS-CoV-2 RNA confirmed in cerebrospinal fluid. $\mathrm{Neu}$ rology 95, 445-449.

[28] Kremer S, Lersy F, de Seze J, Ferre JC, Maamar A, Carsin-Nicol B, Collange O, Bonneville F, Adam G, MartinBlondel G, Rafiq M, Geeraerts T, Delamarre L, Grand S, Krainik A, Caillard S, Constans JM, Metanbou S, Heintz A, Helms J, Schenck M, Lefebvre N, Boutet C, Fabre X, Forestier G, de Beaurepaire I, Bornet G, Lacalm A, Oesterle H, Bolognini F, Messie J, Hmeydia G, Benzakoun J, Oppenheim C, Bapst B, Megdiche I, Henry Feugeas MC, Khalil A, Gaudemer A, Jager L, Nesser P, Talla Mba Y, Hemmert C, Feuerstein P, Sebag N, Carre S, Alleg M, Lecocq C, Schmitt E, Anxionnat R, Zhu F, Comby PO, Ricolfi F, Thouant P, Desal H, Boulouis G, Berge J, Kazemi A, Pyatigorskaya N, Lecler A, Saleme S, Edjlali-Goujon M, Kerleroux B, Zorn PE, Matthieu M, Baloglu S, Ardellier FD, Willaume T, Brisset JC, Boulay C, Mutschler V, Hansmann Y, Mertes PM, Schneider F, Fafi-Kremer S, Ohana M, Meziani F, David JS, Meyer N, Anheim M, Cotton F (2020) Brain MRI findings in severe COVID-19: A retrospective observational study. Radiology 297, E242-E251.

[29] Lin E, Lantos JE, Strauss SB, Phillips CD, Campion TR Jr, Navi BB, Parikh NS, Merkler AE, Mir S, Zhang C, Kamel H, Cusick M, Goyal P, Gupta A (2020) Brain imaging of patients with COVID-19: Findings at an academic institution during the height of the outbreak in New York City. AJNR Am J Neuroradiol 41, 2001-2008. 
[30] Meo SA, Abukhalaf AA, Alomar AA, Al-Hussain F (2021) Magnetic resonance imaging (MRI) and neurological manifestations in SARS-CoV-2 patients. Eur Rev Med Pharmacol Sci 25, 1101-1108.

[31] Steenblock C, Todorov V, Kanczkowski W, Eisenhofer G, Schedl A, Wong ML, Licinio J, Bauer M, Young AH, Gainetdinov RR, Bornstein SR (2020) Severe acute respiratory syndrome coronavirus 2 (SARS-CoV-2) and the neuroendocrine stress axis. Mol Psychiatry 25, 1611-1617.

[32] Kumar A (2018) Editorial: Neuroinflammation and cognition. Front Aging Neurosci 10, 413.

[33] Miskowiak KW, Johnsen S, Sattler SM, Nielsen S, Kunalan K, Rungby J, Lapperre T, Porsberg CM (2021) Cognitive impairments four months after COVID-19 hospital discharge: Pattern, severity and association with illness variables. Eur Neuropsychopharmacol 46, 39-48.

[34] Zhou H, Lu S, Chen J, Wei N, Wang D, Lyu H, Shi C, Hu $S$ (2020) The landscape of cognitive function in recovered COVID-19 patients. J Psychiatr Res 129, 98-102.

[35] Woo MS, Malsy J, Pottgen J, Seddiq Zai S, Ufer F, Hadjilaou A, Schmiedel S, Addo MM, Gerloff C, Heesen C, Schulze Zur Wiesch J, Friese MA (2020) Frequent neurocognitive deficits after recovery from mild COVID-19. Brain Commun 2, fcaa205.

[36] Tay MRJ, Low YH, Lim CCT, Umapathi T, Thio JML, Lui WL, Chan WLW, Chua KSG (2021) Covert subclinical neurocognitive sequelae during the rehabilitation course of severe Coronavirus disease 2019. Am J Phys Med Rehabil 100, 39-43.

[37] Meinhardt J, Radke J, Dittmayer C, Franz J, Thomas C, Mothes R, Laue M, Schneider J, Brünink S, Greuel S, Lehmann M, Hassan O, Aschman T, Schumann E, Chua RL, Conrad C, Eils R, Stenzel W, Windgassen M, Rößler L, Goebel HH, Gelderblom HR, Martin H, Nitsche A, Schulz-Schaeffer WJ, Hakroush S, Winkler MS, Tampe B, Scheibe F, Körtvélyessy P, Reinhold D, Siegmund B, Kühl AA, Elezkurtaj S, Horst D, Oesterhelweg L, Tsokos M, Ingold-Heppner B, Stadelmann C, Drosten C, Corman VM, Radbruch H, Heppner FL (2021) Olfactory transmucosal SARS-CoV-2 invasion as a port of central nervous system entry in individuals with COVID-19. Nat Neurosci 24, 168-175.

[38] Lewis A, Frontera J, Placantonakis DG, Lighter J, Galetta S, Balcer L, Melmed KR (2021) Cerebrospinal fluid in COVID-19: A systematic review of the literature. J Neurol Sci 421, 117316.

[39] Lekgwara P, Kelly A (2020) Evaluating the evidence for direct central nervous system invasion in patients infected with the nCOVID-19 virus. Interdiscip Neurosurg 22, 100829.

[40] Wu Y, Xu X, Chen Z, Duan J, Hashimoto K, Yang L, Liu C, Yang C (2020) Nervous system involvement after infection with COVID-19 and other coronaviruses. Brain Behav Immun 87, 18-22.

[41] Fara A, Mitrev Z, Rosalia RA, Assas BM (2020) Cytokine storm and COVID-19: A chronicle of pro-inflammatory cytokines. Open Biol 10, 200160.

[42] Gandhi S, Srivastava AK, Ray U, Tripathi PP (2020) Is the collapse of the respiratory center in the brain responsible for respiratory breakdown in COVID-19 Patients? ACS Chem Neurosci 11, 1379-1381.

[43] Achar A, Ghosh C (2020) COVID-19-associated neurological disorders: The potential route of CNS invasion and blood-brain relevance. Cells $\mathbf{9}, 2360$.
[44] Desforges M, Le Coupanec A, Dubeau P, Bourgouin A, Lajoie L, Dube M, Talbot PJ (2019) Human Coronaviruses and other respiratory viruses: Underestimated opportunistic pathogens of the central nervous system? Viruses 12, 14 .

[45] Dwivedi D, Megha K, Mishra R, Mandal PK (2020) Glutathione in brain: Overview of its conformations, functions, biochemical characteristics, quantitation and potential therapeutic role in brain disorders. Neurochem Res 45, 1461-1480.

[46] Shukla D, Mandal PK, Ersland L, Gruner ER, Tripathi M, Raghunathan P, Sharma A, Chaithya GR, Punjabi K, Splaine C (2018) A multi-center study on human brain glutathione conformation using magnetic resonance spectroscopy. $J$ Alzheimers Dis 66, 517-532.

[47] Shukla D, Mandal PK, Tripathi M, Vishwakarma G, Mishra $\mathrm{R}$, Sandal K (2020) Quantitation of in vivo brain glutathione conformers in cingulate cortex among age-matched control, MCI, and AD patients using MEGA-PRESS. Hum Brain Mapp 41, 194-217.

[48] Horowitz RI, Freeman PR, Bruzzese J (2020) Efficacy of glutathione therapy in relieving dyspnea associated with COVID-19 pneumonia: A report of 2 cases. Respir Med Case Rep 30, 101063.

[49] Guloyan V, Oganesian B, Baghdasaryan N, Yeh C, Singh M, Guilford F, Ting YS, Venketaraman V (2020) Glutathione supplementation as an adjunctive therapy in COVID-19. Antioxidants (Basel) 9, 914.

[50] Linani A, Benarous K, Yousfi M (2020) Novel structural mechanism of glutathione as a potential peptide inhibitor to the main protease (Mpro): CoviD-19 treatment, molecular docking and SAR study. ChemRxiv, doi: 10.26434/chemrxiv.12153021.v1

[51] Hampe CS, Mitoma H, Manto M (2017) GABA and glutamate: Their transmitter role in the CNS and pancreatic islets. In GABA And Glutamate-New Developments in Neurotransmission Research, Samardzic J, ed. IntechOpen, doi: 10.5772/intechopen.70958

[52] Belousov AB, O'Hara BF, Denisova JV (2001) Acetylcholine becomes the major excitatory neurotransmitter in the hypothalamus in vitro in the absence of glutamate excitation. J Neurosci 21, 2015-2027.

[53] McEwen BS, Eiland L, Hunter RG, Miller MM (2011) Stress and anxiety: Structural plasticity and epigenetic regulation as a consequence of stress. Neuropharmacology $\mathbf{6 2}$, $3-12$.

[54] Meldrum BS (2000) Glutamate as a neurotransmitter in the brain: Review of physiology and pathology. J Nutr 130, 1007S-1015S.

[55] Ghosal S, Hare B, Duman RS (2017) Prefrontal cortex GABAergic deficits and circuit dysfunction in the pathophysiology and treatment of chronic stress and depression. Curr Opin Behav Sci 14, 1-8.

[56] Conde Cardona G, Quintana Pajaro LD, Quintero Marzola ID, Ramos Villegas Y, Moscote Salazar LR (2020) Neurotropism of SARS-CoV 2: Mechanisms and manifestations. J Neurol Sci 412, 116824.

[57] Taquet M, Luciano S, Geddes JR, Harrison PJ (2021) Bidirectional associations between COVID-19 and psychiatric disorder: Retrospective cohort studies of 62354 COVID-19 cases in the USA. Lancet Psychiatry 8, 130-140.

[58] Chiapponi C, Piras F, Piras F, Caltagirone C, Spalletta G (2016) GABA system in schizophrenia and mood disorders: A mini review on third-generation imaging studies. Front Psychiatry 7, 61. 
[59] Jarrahi A, Ahluwalia M, Khodadadi H, da Silva Lopes Salles E, Kolhe R, Hess DC, Vale F, Kumar M, Baban B, Vaibhav K, Dhandapani KM (2020) Neurological consequences of COVID-19: What have we learned and where do we go from here? J Neuroinflammation 17, 286.

[60] Katal S, Gholamrezanezhad A (2021) Neuroimaging findings in COVID-19: A narrative review. Neurosci Lett 742, 135529.

[61] Rapalino O, Weerasekera A, Moum SJ, Eikermann-Haerter K, Edlow BL, Fischer D, Torrado-Carvajal A, Loggia ML, Mukerji SS, Schaefer PW, Gonzalez RG, Lev MH, Ratai EM (2020) Brain MR spectroscopic findings in 3 consecutive patients with COVID-19: Preliminary observations. AJNR Am J Neuroradiol 42, 37-41.
[62] Theberge J, Bartha R, Drost DJ, Menon RS, Malla A, Takhar J, Neufeld RW, Rogers J, Pavlosky W, Schaefer B, Densmore M, Al-Semaan Y, Williamson PC (2002) Glutamate and glutamine measured with 4.0 T proton MRS in nevertreated patients with schizophrenia and healthy volunteers. Am J Psychiatry 159, 1944-1946. 